\title{
ESTADO, EJÉRCITO Y MONOPOLIO FISCAL
}

\author{
Edgardo Dario López Villagral
}

\section{La cuestión del cambio social: cuestiones introductorias}

El sociólogo británico Morris Ginsberg en su artículo denominado "Social Change", publicado por la British Journal of Sociology, definía el concepto de cambio social como una transformación en la estructura social, como por ejemplo el tamaño de una sociedad, la composición o el equilibrio de sus partes o el tipo de su organización. Peter Burke sostiene que la definición de Ginsberg engloba el proceso de cambio económico, político y cultural. Es decir, cualquier modificación de la estructura. Burke también afirma que existen distintos modelos referidos al cambio social. Algunos son cíclicos como el modelo de Sorokin y de las fluctuaciones sociales y culturales, o el de Toynbee o el de Spengler. Asimismo existen modelos lineales como la filosofia de la historia judeo-cristiana y marxista. Burke además, refiriéndose a los modelos lineales, resalta los factores internos del cambio (crecimiento, evolución) o los factores externos (difusión, préstamo e imitación). ${ }^{2}$

Por otra parte, el modelo de Herbert Spencer pone de relieve, sustantivamente, el interés por la evolución social, entendida como un cambio social gradual y acumulativo, principalmente originado desde adentro, y que representa una diferenciación estructural. Resalta el fenómeno del cambio desde lo simple, genético e informal, a lo complejo, especializado y formal.

Herbert Spencer configura los tipos militar e industrial como dos grandes modelos de sociedad. Sir Henry Maine distingue entre una sociedad basada en status y otra que se funda en la figura del contrato. Ferdinand Töennies diferencia en comunidad y sociedad. Howard Becker identifica dos tipos a los cuales designa como sagrado y secular. Robert Redfield emplea la categoría de sociedad urbana y sociedad comunal. ${ }^{3}$

${ }^{1}$ Profesor Titular en Sociología, Cátedra "A". Profesor Adjunto por concurso en Historia Constitucional Argentina, Cátedra "A". Facultad de Derecho y Ciencias Sociales y Políticas. Universidad Nacional del Nordeste. Doctor en Historia de Americana. Universidad de Sevilla.

${ }^{2}$ Burke, P. (1987), Sociología e historia. Alianza Editorial, Madrid, pp. 103-125.

${ }^{3}$ Chinoy, E. (1994), La sociedad, Una introducción a la sociología. Fondo de Cultura Económica, México, p. 120. 
Tanto Max Weber como Émile Durkheim coinciden en gran parte con la visión de Spencer, es decir, el cambio social en términos específicamente evolutivos. Durkheim distingue tipos de solidaridad, reduciendo la solidaridad mecánica a las sociedades simples, y la sociedad orgánica a las sociedades complejas, en relación fundamentalmente a la división del trabajo. Por otro lado, Max Weber ve la historia como un sendero irreversible hacia formas más racionales, complejas e impersonales de organización social, como el capitalismo y la burocracia. El mismo sociólogo norteamericano Talcott Parsons, distingue cinco tipos de sociedad, a saber: primitiva, avanzada, arcaica, intermedia-avanzada, y finalmente la moderna. En estas distinciones se puede percibir con claridad la secuencia evolutiva en estos distintos tipos de sociedad. Peter Burke hace mención a la sociedad tradicional, a la que caracteriza como aquella en la que la jerarquía social se construye en el nacimiento (adscripción), y la movilidad social es baja, en tanto que en la sociedad moderna la jerarquización se basa en el mérito, y la movilidad social es alta. ${ }^{4}$

Peter Burke sostiene que el cambio social se reduce a tres procesos confluyentes: la urbanización, la secularización y la diferenciación estructural. El modelo evolutivo de Spencer se construyó en los años 50, destinado principalmente a explicar el cambio en los países subdesarrollados. Existen historiadores que estudiando el Imperio Romano y las invasiones bárbaras relacionan el cambio social con la decadencia de la urbanidad, la descentralización y el caos en el gobierno, e inclusive el cambio de conductas seculares por otras de tipo místico. Esta última cuestión representaría una contradicción importante en el modelo de modernización de tipo spenceriano. En este sentido Peter Burke aconseja observar a las estructuras sociales tradicionales en un contexto más variado y con factores que resisten al cambio y que en cierta medida se alejan del modelo de la modernización. Es así que este último autor sostiene que el cambio social parece ser multilineal más que unilineal.

Burke afirma, asimismo, que antes de la moda de la teoría de la modernización en los años 50, el sociólogo alemán Norbert Elias había publicado La sociogénesis de la civilización occidental. Elias diferencia dos direcciones principales en los cambios estructurales de la sociedad. Unas tienden hacia una mayor diferenciación e integración. Y otras, lo contrario. Sin lugar a dudas

${ }^{4}$ Almaraz, J. (2013), La teoría sociología de Talcott Parsons. Centro de Investigaciones Sociológicas, Madrid, pp. 488-500. 
Elias expone con mucho énfasis que la integración social es una consecuencia imprevista de la competencia por el poder entre los Estados pequeños en la Edad Media. ${ }^{5}$

En El Gatopardo, la penetrante novela de Lampedusa sobre la Sicilia del siglo XIX, un aristócrata le dice a otro: "Si queremos que todo siga como está, necesitamos que todo cambie" ("Se vogliamo che tutto rimanga come è, bisogna che tutto cambi"). Estas últimas palabras, pronunciadas por uno de los personajes más importantes de la novela, Tancredi Falconeri, representa la capacidad de los sicilianos para adaptarse en el transcurso de la historia a los diferentes gobernantes que ha tenido la isla, pero también encarna la intención de la aristocracia italiana de aceptar la revolución para poder conservar su influencia y poder. ${ }^{6}$

El Gatopardo relata los sucesos ocurridos en la vida de Don Fabrizio Cordera, príncipe de Salina, en Sicilia, tras el desembarco de Garibaldi en aquella isla. La novela está ambientada en la época del Risorgimento. En este sentido, la figura del sociólogo alemán Norbert Elias toma una importante dimensión a través de una literatura sustentado en la descripción y el relato de los cambios que se produjeron en Occidente, fundamentalmente a través de la historia de Francia. ${ }^{7}$ En ella confluyen la sociología, la historia y la política, configurándose de esta manera un espacio con características diferenciales y que merecen un método específico de análisis. ${ }^{8}$

\section{La sociología histórica de lo político 9}

Ives Déloye, politólogo francés, publica en París en 1997 un texto denominado Sociología histórica de lo político (Sociologie historique du politique).

${ }^{5}$ Benninghoff, Federico, "La sociogénesis del Estado en Elias: notas para un debate y apuntes para su aplicación al Chile decimonónico", Universitas humanistica, N ${ }^{\circ} 71,2011$, pp. 27-53; Urteaga, E. (2013), "El pensamiento de Nobert Elias: proceso de civilización y configuración social barataria", Revista Castellano-Manchega de Ciencias Sociales, No 16, pp. 15-31.

${ }^{6}$ Tomasi di Lampedusa, G. (2011), El Gatopardo. Longseller S.A., Buenos Aires.

${ }^{7}$ Ramos Torre, R. (1993), "Problemas metodológicos y textuales de la sociología histórica", REIS, $\mathrm{N}^{\circ} 63$.

${ }^{8}$ Brunet, I. y Morell, A. (2001), "Sociología e historia: Norbert Elias y Pierre Bourdieu", Sociológica, No 4, pp. 109-130; Bejar, H. (1991), "La sociología de Nobert Elias: las cadenas del miedo", REIS, N ${ }^{\circ}$ 56; De la misma autora, "Nobert Elias, retrato de un marginado", REIS, $\mathrm{N}^{\circ} 65,1994$.

${ }^{9}$ Déloye, Y. (2011), Sociologie historique du politique. La Découverte, París. 
Dentro de las ciencias sociales observa el nacimiento de la sociología histórica de lo político. Este espacio científico pretende superar la antinomia entre pasado y presente y las correspondientes entre las disciplinas ideográficas y nomotéticas. Las primeras hacen referencia los estudios dedicados a la comprensión de las particularidades individuales y únicas de los objetos de estudio. Las segundas aluden, en el campo de la sociología, a la comprensión generalizada de un caso dado, que contrastado con la idiográfica, presenta una descripción completa del caso en cuestión. De esta manera, la sociología histórica genera un puente con la ciencia política en donde se transfiere a este último un examen que permite la diferenciación de lo político. La sociología histórica de lo político pretende superar el contraste y la antítesis entre el pasado y el presente.

Déloye sostiene que no existe un espacio exclusivo destinado al estudio histórico, y otro de las mismas características, cuya posesión corresponde a los sociólogos. Continuando con la tradición marxista, Déloye invita a considerar la persistencia del pasado. Examinar y valorar la influencia en el presente, de las acciones y configuraciones sociales pasadas. Sostiene que el pasado impone el presente de las relaciones sociales. La sociología histórica de lo político evita los diseños evolucionistas que conectan el pasado y el presente de forma mecánica. El pasado y el presente están en constante diálogo. Déloye habla de acontecimientos sostenidos por una historia de profundidades políticas, que el investigador debe revelar, y exponer sus conexiones más íntimas. La comprensión de los fenómenos sociales incluye una conectividad dinámica entre el pasado y el presente que se convierten en un fenómeno neurálgico a fin de generar los instrumentos de interpretación de procesos en donde lo recóndito y subterráneo se prolonga en la superficie cronológica.

Déloye sostiene que el objetivo es una conceptualización sistemática de las categorías de análisis de las ciencias políticas. El objeto de la sociología histórica de lo político es pensar la articulación compleja y dinámica de lo político y lo social, de lo global y local.

En resumen:

Una historia social de lo política capaz de establecer las lógicas sociales que operan en la vida política pero también una historia política de lo social apta para identificar la impronta de lo político sobre lo social. Y especialmente, establecer, en la huella de Norbert Elias, las afinidades que existen entre los sistemas políticos (feudales y después estatales) y los 'tipos de economía psíquica' que les corresponden. Esta 
doble perspectiva es esencial: interrogarse sobre las razones históricas y culturales por las que un individuo, una situación, una apuesta es considerado como 'político' en relación a lo 'social' (y recíprocamente): esas son las condiciones primordiales para una aproximación sociohistórica del poder, de las instituciones políticas, del gobierno y del Estado-nación. ${ }^{10}$

Déloye finalmente afirma que esta disciplina joven se abstiene de aislar lo político de lo social, y lo global de lo local. En estas circunstancias, se aboca, entre uno de sus temas preferidos, a los orígenes mismos del Estado moderno. Se tratan temas como la ciudadanía y las identidades nacionales, la cuestión del Estado-Nación (la centralización y descentralización del poder), y la sociología histórica de la civilización electoral, entre otros. Respecto de los aportes de Norbert Elias referentes a la relación entre el ejército y el Estado, Déloye lo explica de la siguiente manera:

Pour Norbert Elias, la genèse de l'État moderne peut être comprise comme une compétition entre plusieurs prétendants à l'hégémonie sur un territoire donné - ainsi, en France, au début du XIV siècle, principalement les rois de France et d'Angleterre, les ducs de Bourgogne et de Bretagne, le comte de Flandres - qui s'achèvera par la victoire de l'un d'entre eux. C'est cette concurrence qui déclenchera le «mécanisme monopoliste». L'accumulation des moyens de domination repose sur deux propriétés principales. La première est le monopole fiscal, qui permet de centraliser l'ensemble des taxes sociales et procure, de la sorte, au souverain la possibilité de rétribuer désormais en argent, et non plus en terres, ses fidèles et serviteurs. La seconde est le monopole établi sur la «violence légitime» (Max Weber) qui attribue tendanciellement au roi l'exclusivité de l'emploi (tant interne qu'externe) de la force militaire. Ce qui le rend maitre et responsable de la pacification interne de la société (la «paix du royaume»). Ces deux monopoles son étroitement imbriqués: les ressources fiscales financent le monopole militaire qui garantit le monopole fiscal. Les deux propriétés, identifiées par Elias en 1939, son également celles que Bloch considérera comme à l'origine de la «reconstitution des États» au cours du second 
âge féodal à savoir l'émergence de la suprématie financière du roi et sa capacité à pacifier la société.

La concentration fiscale et militaire résulte de deux évolutions convergentes: la réduction tendancielle (mains non linéaire dans le temps) du nombre de «groupements de domination» en concurrence et la métamorphose de la forme même de la domination à l'intérieur de l'unité qui devient dominante. La détention durable du monopole fiscal et militaire sur un vaste territoire suppose la mise en place d'une vaste bureaucratie qui favorise ce qu'Elias appelle la «socialisation» du monopole étatique: «les détenteurs du monopole se transforment en simples exécutants d'un appareil administratif aux fonctions multiples»). Devenue centralisée, la domination étatique se dote d'institutions durables (administrations) et se différencie progressivement du reste de la société qu'elle entend désormais gouverner. ${ }^{11}$

En términos introductorios la relación entre el poder militar y el Estado es de vieja data. El sociólogo alemán Norbert Elias, refiriéndose a la misma génesis del Estado en su libro El proceso de la civilización, Investigaciones sociogenéticas y psicogenéticas, realiza importantes aportes a esta cuestión. ${ }^{12} \mathrm{El}$ profesor francés Yves Déloye, comentando su obra (mencionada antes) sostiene que "El Estado moderno, puede concebido como una competencia entre varios pretendientes a la hegemonía de un territorio determinado (principalmente en Francia a comienzos del siglo XIV)". Elias defiende la idea de que esta competencia desembocaría en el mecanismo monopolista. Esta se sostiene en dos propiedades fundamentales: el monopolio fiscal, es decir la centralización del cobro de impuestos que permite al Rey retribuir a sus siervos en dinero y el monopolio de la violencia legítima (exclusividad del uso de la manu militari). ${ }^{13}$ Déloye sostiene que estos dos monopolios están íntimamente relacionados. Los

${ }^{11}$ Ibídem, p. 33.

${ }^{12}$ Capdevielle, J. (2012), "La sociología figuracional de Norbert Elias y el estructuralismo genético de Pierre Bordieu: encuentros y desencuentros", Aposta: Revista de ciencias sociales, No 52, pp. 1-23.

${ }^{13}$ Guerra Manzo, E. (2013), "Civilización y violencia en la obra de Norbert Elias", Iztapalapa: Revista de Ciencias Sociales y Humanidades, N. 74, pp. 129-154; Jurado Jurado, J. C. (2004), "Sobre el proceso de la civilización de Norbert Elias", Nómadas, Revista Crítica de Ciencias Sociales y Jurídicas, $\mathrm{N}^{\circ} 10$, pp. 1-11. 
recursos fiscales financian el monopolio militar que ciertamente garantizan el propio monopolio fiscal.

Agrega también que la detentación durable del monopolio fiscal y militar favorece a la creación de una burocracia. A esto denomina Elias la socialización del monopolio estatal. De esta manera la cuestión militar estuvo implicada necesariamente en la misma formación del Estado. Autores como Elias, tomando como ejemplo la historia de Francia, han podido dilucidar este complejo universo de relaciones políticas y el mismo nacimiento del Estado francés. Con el surgimiento de los regímenes absolutistas en Europa, se abandonó la modalidad administrativa asentada en los pequeños núcleos de servidores domésticos que secundaban a los príncipes en el gobierno de sus dominios y se dio lugar a la conformación y expansión de grandes estructuras administrativas que comenzaron a guardar un carácter público. ${ }^{14}$ Esto supuso una evidente concentración de poder en los soberanos, lo que derivó de dos procesos concomitantes y mutuamente condicionados, a saber, la competición político-militar entre los príncipes, que tuvo como consecuencias la constitución de enormes formaciones militares permanentes, y las exigencias financieras que ello supuso. Las burocracias civiles se establecieron para organizar, optimizar y robustecer la presión fiscal sobre las poblaciones controladas a los efectos de obtener el financiamiento necesario para hacer frente a las guerras que enmarcaron la formación de los Estados nacionales. ${ }^{15}$

El politólogo italiano Ángelo Panebianco manifiesta que existe una ceñida relación entre el paso de las milicias alistadas a través de contratos con agentes militares privados, a los ejércitos profesionales y permanentes, y el paso de la financiación del Estado por medio de banqueros privados, a la financiación mediante la medra continua del aparato fiscal ${ }^{16}$ Burocracia civil y organización militar permanente se refuerzan de manera conjunta en la Europa Occidental y su desarrollo está estrechamente relacionada desde el principio. Pierre Bourdieu sostiene que la génesis del Estado es inherente al proceso de unificación

${ }^{14}$ Anderson, P. (1998), El Estado Absolutista. Siglo XXI Editores, 1982, Madrid, pp. 1012; Elias, N. (1998), "Los procesos de formación del Estado y de construcción de la Nación", Historia y sociedad, $\mathrm{N}^{\circ} 5$, pp. 101-117.

${ }^{15}$ González, F. E. (2004), “A propósito de 'Las palabras de la guerra': los comienzos conflictivos de la construcción del Estado Nación y las guerras civiles de la primera mitad del siglo XIX", Estudios Políticos, N ${ }^{\circ} 25$, pp. 37-70.

${ }_{16}$ Panebianco, Á. (1995), "Las burocracias públicas", en Pasquino, Gianfranco y otros, Manual de ciencia politica. Alianza Editorial, Madrid, pp. 375-376. 
de los distintos campos (sociales, económicos, culturales, políticos, militares) que sobreviene a la constitución gradual de un monopolio estatal de la violencia física y simbólica legítima. Esto se debe a que frente a un conjunto de recursos materiales y simbólicos, el "Estado está en condiciones de regular el funcionamiento de los diferentes campos, ya sea a través de las intervenciones financieras o a través de las intervenciones jurídicas". ${ }^{17}$

El Estado no solamente reivindica con éxito el monopolio del empleo legítimo de la violencia física sino también el de la violencia simbólica. Así, el Estado resulta de la concentración histórica de diferentes tipos de capital, tales como el capital de la fuerza física, el capital económico, el capital cultural, el capital simbólico, delimitando un campo de poder en cuyo escenario se entretejen una serie de confrontaciones y luchas que, de modo directo o indirecto, señalan particularmente al control del Estado y, desde él, al control del campo y de los intercambios y de las correlaciones de fuerzas que se originan en él. Esto genera, en cierta medida, un nuevo tipo de capital, es decir, el "capital estatal". Por lo tanto, de ello resulta que el desarrollo del Estado va parejo con el desarrollo del campo del poder, entendido como un espacio de juego en el que los poseedores de capital (de los diversos tipos) bregan particularmente por el poder sobre el Estado, es decir, sobre el capital estatal que otorga poder sobre las variadas formas de capital, y sobre su reproducción (particularmente sobre la institución de la educación).

Bourdieu reconoce que, en sus orígenes, el Estado moderno debió reafirmar su fuerza física frente a otras formaciones estatales en nacimiento y también frente a sucesivos "contrapoderes" interno que resistieron aquella concentración. Las fuerzas armadas de ese Estado se diversificaron y se conformaron, así, en "fuerzas militares" a cargo de la defensa exterior del Estado y en "fuerzas policiales" a cargo del mantenimiento del "orden interior" del mismo. Pero esta concentración de "capital de fuerza física" requiere de la conformación de una "fiscalidad" eficiente mediante la cual fue posible la recaudación impositiva que permitió el financiamiento de los imperativos de la defensa y la seguridad interior. Ello dio lugar a una "causalidad circular" entre la institucionalización de los impuestos, ya que éstos eran cobrados a los súbditos con el fin de mantener a aquellas fuerzas, y éstas servían, al mismo tiempo, de instancia de coerción que permitía vencer las sucesivas resistencias internas que se interponían al cobro de

${ }^{17}$ Bourdieu, P. (1999), Razones Prácticas. Sobre la teoría de la acción. Anagrama, Barcelona, p. 50 . 
esos impuestos. Del mismo modo, esto generó la conformación de un "capital simbólico" asentado en el reconocimiento de la legitimidad de aquellas fuerzas armadas y de las recaudaciones oficiales, y todo, en su conjunto, contribuyó con la unificación del territorio, es decir, de un territorio sometido a una misma fiscalidad y fue parejo con la concentración del "capital informacional" acerca del conjunto social, especialmente a través de las estadísticas económicas y poblacionales y de la cartografia territorial. Lo que a su vez trajo aparejado la conformación del mercado cultural mediante la unificación de los códigos y de las estructuras lingüísticas y jurídicas y la homogenización de las formas de comunicación y de las estructuras burocráticas. En ello jugaron un rol central las estructuras escolares inculcando y transmitiendo una "cultura nacional legítima". De esta manera, el Estado se fue constituyendo bajo la protección de la concentración de estos diversos tipos de capital y, en su marco, fue fundiendo un conjunto de "estructuras mentales" que engloban principios de enfoque y de división comunes, formas de pensamiento y de percepción comunes, entre otros.

Pierre Bourdieu afirma que en este esquema de concentración, el capital simbólico, es decir, cualquier tipo de capital, físico, económico, cultural, social, cuando es descubierto por operadores sociales cuyas categorías de percepción son de tal naturaleza que les hacen posible conocerla (distinguirla) e identificarla, concederle "algún valor", establece una etapa estructurante elemental, ya que funciona como categoría o como escolta de los demás tipos de concentración de capital. Y, en particular, la representación objetivada y regulada de ese capital simbólico, que está establecida por el capital jurídico, cuya concentración significó un proceso de diferenciación que confluyó en la conformación de un "campo jurídico autónomo".

De este modo, el Estado no condensa apenas un proceso de concentración de la fuerza física sino también de concentración afines de la fuerza simbólica conformada en "estructuras cognitivas" que encierran formas de percepción, de clasificación y de significación de las cosas del mundo y, en particular, de las estructuras sociales, sin olvidar que se trata de estructuras cognitivas históricamente constituidas y cuyos efectos básicos involucran la creación de un basamento de legitimidad y consenso a favor del Estado.

Tal como afirma Ana María Lorandi, el asunto es cómo concebir al Estado. ${ }^{18}$ La definición de Bourdieu colabora en la visualización de este concepto con mayor claridad:

${ }^{18}$ Lorandi, A. M. (2008), Poder central, poder local. Funcionarios borbónicos en el Tucumán colonial. Un estudio de antropología política. Prometeo Libros, Buenos Aires, pp. 207-209. 
El Estado es el resultado de un proceso de concentración de los diferentes tipos de capital, capital de fuerza física o instrumentos de coerción (ejército, policía) capital económico, capital cultural o mejor dicho, informacional, capital simbólico, concentración que, en tanto tal, convierte al Estado en una especie de meta-capital otorgando poder sobre las demás clases de capital y sobre sus poseedores. ${ }^{19}$

Por ello fue necesario edificar un sistema de gobierno, un cuerpo de funcionarios, que hablaran y actuaran en nombre del monarca, pero que ya no se confundiera con él. De allí que ese poder resultase en un monopolio que se fue alcanzando a expensas de otros competidores que ejercían ese poder con anterioridad. Tal como manifiesta Norbert Elias las luchas se plantearon entre los que pretendían ejercer ese monopolio y los que lo detentaban con anterioridad y, a la vez, es necesario identificar "dónde habrán de reclutarse (los agentes) y cómo habrá de repartir las cargas y beneficios". ${ }^{20}$

\section{Conclusiones}

A partir de las afirmaciones sostenidas por los distintos autores que han participado en este artículo, se pueden inferir las íntimas relaciones existentes entre el nacimiento del Estado moderno y la milicia. Queda claro que los aportes de Norbert Elias han sido esclarecedores, sobre todo en los aportes realizados en su célebre texto El proceso de la civilización. Investigaciones sociogenéticas y psicogenéticas. Este texto, que vio la luz en su edición alemana en el año 1977, describe el momento exacto en que el monopolio fiscal y el monopolio militar sustentan la formación del Estado moderno. Tomando como ejemplo la historia francesa, Norbert Elias obtiene esa valiosa información en un contexto puramente medieval y que hoy nos permite visualizar ese fenómeno con mayor significancia.

Otros autores de la talla de Pierre Bourdieu, utilizando el concepto de campo, ubican a ese fenómeno en un espacio donde confluyen distintas fuerzas que compiten entre sí, asociándolo también con el denominado campo jurídi-

${ }^{19}$ Bourdieu, Pierre, ob. cit., pp. 99-101.

${ }^{20}$ Elias, Norbert, El proceso de la civilización. Investigaciones sociogenéticas y psicogenéticas, Fondo de Cultura Económica, 1996, Buenos Aires, p. 345 
co y campo político. La cuestión del cambio social, el Estado y las milicias constituyen un eje fundamental de una disciplina naciente como la sociología histórica de lo político. En esta cuestión, se ha puesto relevancia el importante aporte que hace Yves Déloye con su texto Sociologie historique du politique. De esta manera, los aportes de Norbert Elias, de Bourdieu, y hasta del mismo Peter Burke, se engloban dentro de un espacio cuya especificidad está marcada por esta flamante disciplina.

\section{Bibliografía}

Almaraz, J. (2013), La teoría sociología de Talcott Parsons. Centro de Investigaciones Sociológicas, Madrid.

Anderson, P. (1998), El Estado Absolutista. Siglo XXI Editores, 1982, Madrid, pp. $10-12$.

Bejar, H. (1991), "La sociología de Nobert Elias: las cadenas del miedo", REIS, $\mathrm{N}^{\mathrm{0}} 56$.

Bejar, H. (1994), "Nobert Elias, retrato de un marginado", REIS, $\mathrm{N}^{\circ} 65$.

Benninghoff, F. (2011), "La sociogénesis del Estado", en Elias: Notas para un debate y apuntes para su aplicación al Chile decimonónico, Universitas humanistica, $\mathrm{N}^{\circ}$ 71, pp. 27-53.

Bourdieu, P. (1999), Razones Prácticas. Sobre la teoría de la acción. Anagrama, Barcelona.

Brunet, I. y Morell, A. (2001), "Sociología e historia: Norbert Elias y Pierre Bourdieu", Sociológica, No 4, pp. 109-130.

Burke, P. (1987), Sociología e historia. Alianza Editorial, Madrid.

Capdevielle, J. (2012), "La sociología figuracional de Norbert Elias y el estructuralismo genético de Pierre Bordieu: encuentros y desencuentros", Aposta: Revista de ciencias sociales, $\mathrm{N}^{0} 52, \mathrm{pp} .1-23$.

Chinoy, E. (1994), La sociedad, Una introducción a la sociología. Fondo de Cultura Económica, México.

Déloye, Y. (2011), Sociologie historique du politique. La Découverte, París.

Elias, N. (1996), El proceso de la civilización. Investigaciones sociogenéticas y psicogenéticas. Fondo de Cultura Económica, Buenos Aires.

Elias, N. (1998), "Los procesos de formación del Estado y de construcción de la Nación", Historia y sociedad, $\mathrm{N}^{\circ}$ 5, pp. 101-117. 
González, F. E. (2004), “A propósito de 'Las palabras de la guerra': los comienzos conflictivos de la construcción del Estado Nación y las guerras civiles de la primera mitad del siglo XIX", Estudios Politicos, No 25, pp. 37-70.

Guerra Manzo, E. (2013), "Civilización y violencia en la obra de Norbert Elias", Iztapalapa: Revista de Ciencias Sociales y Humanidades, $\mathrm{N}^{\circ} .74$, pp. 129-154.

Jurado Jurado, J. C. (2004), "Sobre el proceso de la civilización de Norbert Elias", Nómadas, Revista Crítica de Ciencias Sociales y Jurídicas, $\mathrm{N}^{\mathrm{o}} 10$, pp. 1-11.

Lorandi, A. M. (2008), Poder central, poder local. Funcionarios borbónicos en el Tucumán colonial. Un estudio de antropología política. Prometeo Libros, Buenos Aires.

Panebianco, Á. (1995), "Las burocracias públicas", en Pasquino, Gianfranco y otros, Manual de ciencia política. Alianza Editorial, Madrid.

Ramos Torre, R. (1993), "Problemas metodológicos y textuales de la sociología histórica", REIS, No 63.

Tomasi di Lampedusa, G. (2011), El Gatopardo. Longseller S.A., Buenos Aires.

Urteaga, E. (2013), "El pensamiento de Nobert Elias: proceso de civilización y configuración social barataria", Revista Castellano-Manchega de Ciencias Sociales, $\mathrm{N}^{\mathrm{o}} 16$, pp. 15-31. 